\title{
Promotion Behavior for Ecotourism of Sub-district Administration Organization Member in Thailand
}

\author{
Assist. Prof. Dr. Paitoon Pimdee \\ Industrial Education Program, Faculty of Industrial Education, \\ King Mongkut's Institute of Technology Ladkrabang, \\ Bangkok, Thailand, 10520 \\ kppaitoo@gmail.com
}

\section{Dr. Pitak Paksanondha}

Retired Government Official, Royal Irrigation Department, Ministry of Agriculture and Cooperatives

Bangkok, Thailand, 10300

pppitak@hotmail.com

\section{Doi:10.5901/mjss.2013.v4n2p81}

\section{Abstract}

The research objective was to study and compare promotion behavior for ecotourism of Sub-district Administration Organization (SAO) according to variables of sex, age, education level, family status and tourism. The multi-stage random sampling technique was used for data collecting for $800 \mathrm{SAO}$ members from overall country. The reliability of promotion and conservation of tourism site and regulation control were 0.79 and 0.84 respectively. Data analysis was done with the descriptive statistics of percentage, mean, standard deviation, and inferential statistics with $t$-test. The results revealed that SAO member had promotion behavior for ecotourism in holistic view at rather high level. The SAO member with different age had different whole promotion behavior for ecotourism with statistically significant at level of 0.05 . SAO member with different sex, age had different promotion and conservation of tourism site aspect with statistically significant at level of $0.05,0.05$ and 0.05 respectively. Moreover, SAO member with different education level and family economic status had different regulation control behavior with statistically significant at level of 0.05 and 0.05 .

Key words:tourism behavior/ ecotourism/ Sub-district Administration Organization member

\section{Introduction}

Thailand is a country with high potential and enrich for tourism. This is information from Tourism Authority of Thailand and it has also been found that tourism is an industry that creates very huge income for country. The rapid growth rate of tourism industry and the large amount of tourists has increased incessantly. These have caused the degradation of tourism resources in terms of natural resources and environmental quality. Therefore, the governmental sectors in different regions of country have tried to arrange the new model activities to conserve and protect the tourism site such as ecotourism, agro-tourism and so on. Especially, ecotourism was introduced and has accepted widely overall country because it is a tourism activity that Tourism Authority of Thailand has pushed it up continuously for about two decades. It is also a tourism that conserves natural resource and environment with aim of no environmental pollution, nuisance or environment and culture destruction. Additionally, it has increased the social and economic benefit or directly and indirectly distributed the various benefit to local community with the aim to develop country to be society of sustainable happiness.

SAO has been established according to Act of Sub-district Administration Organization B.E. 2542 and it is a local government. SAO member is elected by people in each sub-district with an import task of protect, take care and maintain the natural resources and environment, therefore arrangement of community ecotourism is an excellent activity to support that task. This will lead to sustainable natural resources and environment for community and give high advantage to 
community including pushing and stimulating the stakeholders in industrial tourism section and tourist to aware and perceive the occurrence of environmental problem. For this reason, they will turn back to pay attention for protection and conservation the environment in order to keep the community tourism sustainably.

The essentials mentioned above, it is reason of this research to study the promotion behavior for ecotourism by studying and comparing promotion behavior in terms of promotion and conservation of tourism site and regulation control for ecotourism of SAO member who had different socio-biological characteristics. The knowledge gained from this research will be beneficial for basic information to set guideline for development of promotion behavior for ecotourism of SAO member further.

\section{Research Objective}

To compare the promotion behavior for ecotourism of SAO member with different sex, age, education level, family economic status, and tourism.

\section{Research Hypothesis}

SAO member with different sex, age, education level, family economic status, and tourism has different promotion behavior for ecotourism.

\section{Methodology}

\subsection{Population}

Population was 67,460 SAO members of 6,746 sub-districts in B.E. 2551 overall country. Sample size was calculated according to Yamane, formula (Yamane, 1973) atconfident interval of $95 \%$ and error with $5 \%$. The obtained sample group was 800 SAO members and the sample group was collected by Multi-stage random sampling technique.

\subsection{Variables used in the study}

\section{1) Independent Variables}

They weresocio-biological characteristics ofSAO members that composed of sex, age, education level, family economic status, and tourism.

\section{2) Dependent Variable}

It was promotion behavior for ecotourism that composed of promotion and conservation of tourism site and regulation control.

\subsection{Research tool}

It was questionnaire that composed of socio-biological characteristics with sex, age, education level, family economic status, and tourism and promotion behavior for ecotourism with promotion and conservation of tourism site and regulation control. It was try out with the $50 \mathrm{SAO}$ members with similar characteristic to sample group. The reliability was 0.79 and 0.84 that determined by Cronbach' coefficient (Cronbach, 1951).

\subsection{Data Collection}

The data were collected from sample group of 800 SAO members in B.E. 2551 through mail sending and the 658 questionnaire were received back. It was $82.25 \%$ responses. 


\subsection{Data Analysis}

The descriptive statistics with percentage, mean, and standard deviation were used for description. The inferential statistics with Independent Samples t-test was employ for hypothesis testing.

Table 1 Criterion for Interpretation of Mean Level of Promotion Behavior for Ecotourism

\begin{tabular}{|c|c|}
\hline Rang of Mean & Level of Promotion Behavior \\
\hline $1.00-1.49$ & Very Low \\
$1.50-2.49$ & Low \\
$2.50-3.49$ & Rather Low \\
$3.50-4.49$ & Rather High \\
$4.50-5.49$ & High \\
$5.50-6.00$ & VeryHigh \\
\hline
\end{tabular}

\section{Research Results}

Table 2 Number and Percentage of Socio-biological Characteristics of Sample Group

\begin{tabular}{|c|c|c|c|}
\hline \multicolumn{2}{|c|}{ Socio-biological Characteristics } & \multirow{2}{*}{$\begin{array}{c}\text { Number } \\
439\end{array}$} & \multirow{2}{*}{$\begin{array}{c}\text { Percentage } \\
66.72\end{array}$} \\
\hline 1. Sex & Male & & \\
\hline & Female & 219 & 33.28 \\
\hline & Total & 658 & 100 \\
\hline \multirow{3}{*}{ 2. Age } & Less (Lesser than or equal to 39years) & 325 & 49.39 \\
\hline & More (Morethan 39 years) & 333 & 50.61 \\
\hline & Total & 658 & 100 \\
\hline \multirow[t]{3}{*}{ 3. Education Level } & Lower than Bachelor & 320 & 48.63 \\
\hline & Bachelorand higher & 338 & 51.37 \\
\hline & Total & 658 & 100 \\
\hline \multirow[t]{3}{*}{ 4. Family Economic status } & Low & 362 & 55.02 \\
\hline & High & 296 & 44.98 \\
\hline & Total & 658 & 100 \\
\hline \multirow[t]{3}{*}{ 5. Tourism } & Less (Not more than 2 times/year) & 402 & 61.09 \\
\hline & More (More than 2 times/year) & 256 & 38.91 \\
\hline & Total & 658 & 100 \\
\hline
\end{tabular}

Sample group of SAO members who answered the questionnaires were male with 439 members (66.72\%) and were female with 219 members (33.28\%).

Sample group of SAO members who answered the questionnaires had age morethan 39 years with 333 members $(50.61 \%)$ and had age lesser than or equal to $39 y e a r s$ with 325 members $(49.39 \%)$.

Sample group of SAO members who answered the questionnaires had education level of bachelor and higher than bachelor with 338 members (51.37\%) and had level of lower than bachelor with 320 members (48.63\%).

Sample group of SAO members who answered the questionnaires had low family economic status (income not more than 15,000Baht/month and family member more than 6 peoples) with 362 members (55.02\%) and had high family economic status (income more than 15,000Baht/month and family member not more than 6 peoples) with 296 members (44.98\%).

Sample group of SAO members who answered the questionnaires had tourism not more than 2 times/year with 402 members $(61.09 \%)$ and had tourism more than 2 times/year with 256 members $(38.91 \%)$. 
Table 3 Promotion Behavior for Ecotourismof SAO members

\begin{tabular}{|l|c|c|c|}
\hline Behavior & M & S & Level \\
\hline Promotion and conservation of tourism site & 3.87 & 0.70 & Rather High \\
Regulation control & 4.72 & 0.66 & High \\
\hline Overall & 4.29 & 0.55 & Rather High \\
\hline
\end{tabular}

SAO membershad promotion behavior for ecotourismin aspect of Promotion and conservation of tourism site with rather high level and regulation control with high level and overall behavior with rather high level.

Table 4 Comparison of Mean of Promotion Behavior for Ecotourismof SAO members with Different Socio-biological Characteristics

\begin{tabular}{|c|c|c|c|c|c|c|c|c|c|c|c|c|}
\hline \multirow[t]{2}{*}{ Variables } & \multicolumn{4}{|c|}{$\begin{array}{l}\text { Promotion and } \\
\text { conservation of } \\
\text { tourism site }\end{array}$} & \multicolumn{4}{|c|}{ Regulation Control } & \multicolumn{4}{|c|}{ Overall } \\
\hline & M & $S$ & $t$ & Sig. & $M$ & $S$ & $t$ & Sig. & $M$ & $S$ & $t$ & Sig. \\
\hline $\begin{array}{l}\text { 1. Sex } \\
\text { Male }\end{array}$ & 3.95 & 0.67 & \multirow[b]{2}{*}{$4.89^{* \star}$} & \multirow[b]{2}{*}{0.00} & 4.70 & 0.66 & \multirow[b]{2}{*}{-0.85} & \multirow[b]{2}{*}{0.39} & 4.32 & 0.52 & \multirow[b]{2}{*}{1.59} & \multirow[b]{2}{*}{0.11} \\
\hline Female & 3.65 & 0.72 & & & 4.75 & 0.68 & & & 4.20 & 0.59 & & \\
\hline $\begin{array}{l}\text { 2. Age } \\
\text { Less }\end{array}$ & 3.70 & 0.64 & \multirow{2}{*}{$\begin{array}{c}- \\
5.76^{* *}\end{array}$} & \multirow[b]{2}{*}{0.00} & 4.74 & 0.69 & \multirow[b]{2}{*}{0.39} & \multirow[b]{2}{*}{0.69} & 4.22 & 0.52 & \multirow[b]{2}{*}{$-2.36^{*}$} & \multirow[t]{2}{*}{0.02} \\
\hline More & 4.02 & 0.70 & & & 4.72 & 0.64 & & & 4.36 & 0.55 & & \\
\hline $\begin{array}{l}\text { 3. Education } \\
\text { Low }\end{array}$ & 3.96 & 0.71 & \multirow[b]{2}{*}{$3.61^{* \star}$} & \multirow[b]{2}{*}{0.00} & 4.64 & 0.68 & \multirow[b]{2}{*}{$-2.67^{*}$} & \multirow[b]{2}{*}{0.01} & 4.29 & 0.56 & \multirow[b]{2}{*}{-0.22} & \multirow[b]{2}{*}{0.83} \\
\hline High & 3.75 & 0.68 & & & 4.79 & 0.65 & & & 4.26 & 0.54 & & \\
\hline $\begin{array}{l}\text { 4. Economic status } \\
\text { Low }\end{array}$ & 3.82 & 0.69 & \multirow[b]{2}{*}{-1.29} & \multirow[b]{2}{*}{0.20} & 4.81 & 0.65 & \multirow[b]{2}{*}{$3.57^{* *}$} & \multirow[b]{2}{*}{0.00} & 4.31 & 0.54 & \multirow[b]{2}{*}{1.91} & \multirow[b]{2}{*}{0.06} \\
\hline High & 3.90 & 0.71 & & & 4.61 & 0.67 & & & 4.25 & 0.56 & & \\
\hline $\begin{array}{l}\text { 5. Tourism } \\
\text { Less }\end{array}$ & 3.85 & 0.73 & \multirow{2}{*}{-0.73} & \multirow{2}{*}{0.46} & 4.73 & 0.61 & \multirow{2}{*}{-0.05} & \multirow[b]{2}{*}{0.96} & 4.28 & 0.55 & \multirow[b]{2}{*}{-0.42} & \multirow[b]{2}{*}{0.67} \\
\hline More & 3.90 & 0.68 & & & 4.74 & 0.70 & & & 4.31 & 0.58 & & \\
\hline
\end{tabular}

${ }^{*}$ Sig. $<.05$ and $^{* *}$ Sig. $<.01$

Sample group of SAO members who had different age had different promotion behavior for ecotourism in holistic view with statistically significant at 0.5 level. Moreover, SAO members who had different sex, age and education level had different behavior in aspect of promotion and conservation of tourism site with statistically significant at 0.5 level and SAO members who had different education level and family economic status had different behavior in aspect of regulation control with statistically significant at 0.5 level.

\section{Discussions}

From the above results, the findings have various benefits for development of promotion behavior for ecotourism of SAO members that can be discussed according to hypothesis as the followings.

1) The results revealed that SAO members had in aspect of promotion and conservation of tourism site $(M=3.87)$ and holistic view $(M=4.29)$ at rather high levels and behavior in aspect of regulation control $(M=4.72)$. It might be that they are the local governmental administration committee and they understand the regulation very well. Therefore they should be a good model for other people to perform themselves to follow the regulation of tourism site or law of conservation of natural resources and environment in the tourism site. Furthermore, they should not degrade environment 
or make any pollutions at tourism site. Consequently, behavior in aspect of promotion and conservation of tourism site, they should also act as good citizen and SAO members to preserve the surrounding environment of tourism site to be sustainable as prior or aid to rehabilitate the natural resources and tourism sites including supporting the others to do by suggesting or prohibit. However, this activity might be difficult to do but they might be easily to use the local regulation to control the people to follow the regulation or rules of tourism site. Therefore, it affected to their behavior of regulation control were at rather high level and it is congruent to the study of Kerstetter, et al (2004) on behavior of ecotourism of people in Taiwan was conducted with people who is 18 years old and older. He revealed that tourist had ecotourism behavior in each item between rather high and high (Mean between4.03-5.16). Moreover, the result is also pertinent to the study of Swattikul (2005) who studied the ecotourism behavior of tourist at Kaeng Krachan National Park, Phetchaburi Province in Thailand found that tourist had tourism behavior in at Kaeng Krachan National Park at high level but it is not in the line with the study of Nawajaroenkul (1998) who studied on ecotourism behavior of Thai tourist at Sai Yok National Park, Kanchanaburi Province revealed that Thai tourist had ecotourism behavior at moderate level and study of Watthamanee (1999) who studied the relationship between media receiving on ecotourism and knowledge attitude and behavior of undergrad student in Bangkok Metropolis, revealed that undergrad student had ecotourism at moderate level as well.

2) The results illustrated that SAO members with different sex had different promotion and conservation of tourism site with statistically significant at level of 0.05 . It might be that the SAO members with different sex had different interesting to study on environment with different world view and perception, therefore it might cause them to have different promotion and conservation of tourism site. This is pertinent to study of Theepapal (1999) mentioned that the difference between people is an essential internal factor and had direct effect to consumption behavior and it is also congruent to Klabchum (1991) studied on knowledge and behavior of teacher student on environmental pollution in Bangkok. The finding showed that behavior of environmental pollution in Bangkok of teacher student depended on sex with statistically significant at 0.05 level and the research result of Weerachaya (2003) studied on media receiving, knowledge, attitude and consumption behavior of environmentally friendly product: A case study of the forth year undergrad student, Kasetsart University. It was found that consumption behavior of environmentally friendly product between male and female students were different with statistically significant at 0.05 level.

SAO members with different age had different promotion and conservation of tourism site with statistically significant at level of 0.05 . It might be that the SAO members with different age had different experiences since age is a indicator of maturity of both physical and mind. This is congruent to theory of social categories theory that concluded that person with similar social characteristics sex, age, income, and education level, etc.) would had similar communication behavior (De Fleur. 1966). This is also in the line with research of Prapannetivuth and Arttacharija (2008) found that Thai tourist with age between 35-49 years old and older than 65 years sold would have more responsible behavior toward environment more than other age groups. Moreover, Junton and et al (2004) studied on the factors influencing to participation of local community in tourism management of ecotourism in Area of Mae Klong River, Ratchaburi Province. The finding discovered that age had influence to participation of local community in tourism management of ecotourism. Additionally, it is also in accordance with the study of Suwattikul (2005) who studied on ecotourism behavior of tourist at Kaeng Krachan National Park, Phetchaburi Province found that majority of tourist had knowledge on ecotourism at good level and behavior at high level and tourist with different age had different ecotourism behavior with statistically significant at 0.05 level and it is congruent to the study of Nawajaroenkul (1998) who studied on ecotourism behavior of Thai tourist at Sai Yok National Park, Kanchanaburi Province revealed that Thai tourist had ecotourism behavior at moderate level and age had effect to ecotourism behavior and it is similar to the research of Petcharoen (2000) who studied guideline of people participation in Bangkok Area toward consumption behavior of green label product by conducting interview with 400 people in Bangkok. Then, it revealed that different age caused different participation in every activity, particularly, sample group with age between 34-42 years old had highest participation in every activity. Besides, it also discovered that the demand to participate of people in every activity was different according to age the sample with age between 3442 years old had more demand than other groups.

SAO members with different education level had different promotion and conservation of tourism site and behavior regulation control with statistically significant at 0.05 and 0.05 levels. This might be that the education level reflect to the knowledge existing and perception on fact about environmental problem that threaten them at present, therefore it awakes them to realize and raise their awareness to change attitude and express behavior for natural resources and environment conservation. Consequently, they are able to transfer the knowledge to others to follow them to practice for natural resources and environment conservation and comply according to regulation. It is relevant to social categories theory that concluded that people with similar socio-biological characteristic (sex, age, income, education level and so on) 
would have the parallel to communication behavior (De Fleur. 1966). There is a research about the relationship between knowledge and behavior of Petcharoen (2000) studied on guideline of people participation in Bangkok area toward consumption behavior of green label product. Data collection was conducted by interviewing with 400 people in Bangkok. Then, it revealed that different education level caused different participation in every activity, particularly, sample group with education level of diploma/high vocational had highest participation in every activity. Besides, it also discovered that the demand to participate of people in every activity was different according to education level with bachelor or higher had more demand than other groups. Moreover, it is also congruent Boripis (2005) who studied the role of SAO members for ecotourism promotion of Samuth Prakarn Province. It was fond that education level correlated to the role of SAO members with statistically significant at 0.05 level and the different education level had different role of SAO members with statistically significant at 0.05 level.

Additionally, SAO members with different family economic status had different behavior of regulation control with statistically significant at level of 0.05 . It might be that the different family economic status affects to activity inside family that has the learning process and parents and relatives to be role model for natural resources and environment conservation such as behavior of resource utilization with maximization of highest profit and behavior of waste reduction. It is congruent to the studies of Thiengkamol (2011i) on development of model of environmental education and inspiration of public consciousness influencing to global warming alleviation revealed the environmental behavior for global warming alleviation composing of consumption behavior, energy conservation behavior waste management behavior, recycling behavior, traveling behavior and environmental knowledge transferring was affected by environmental education through inspiration of public consciousness in terms of role model and the concept of Kotler (1994) who explained that consumption behavior depended on factors of two groups that are influence of social power and influence of psychological power. The factors in the group of influence of social power, "Social Class" is the important group by gathering the people who has similar behavior with economic fundament as criterion. Social class would specify the position within the social class that directly related to consumption behavior since consumption patternoften directly related to social class. Generally, members in the same social class would have the similar behavior, value, and belief on consumption pattern. Moreover, people who are under similar social class often buy the same type of product from the same type of shop and receive the same type of media. This is also harmonious to the research of Songserm (2001) who studied the psychological factors of consumer to predict the ecotourism behavior of tourist in Chiang Mai Province. The finding showed that income correlated to ecotourism behavior of tourist in Chiang Mai Province with statistically significant at level of 0.05 and income factor was able to predict ecotourism behavior of tourist in Chiang Mai Province with statistically significant at level of 0.05 .

\section{Recommendations}

1. The related work unit should hold activity to promote and develop the promotion behavior for ecotourism with emphasizing on development of creative and supportive behaviors to conserve the tourism site among the group of SAO members who have low supportive and conservation behaviors such as old age group and female sex.

2. It should be researched by using the prior concept but it might be change to be other target groups such as youth leader, other community leader groups, or people in community.

3. It should be researched in the same characteristics again by studying on the psychological factors of psychological trait and psychological state or other situational variables that might be expected to effect toward promotion behavior for ecotourism of SAO members.

\section{References}

Boripis, T. (2005). The Role of Sub-district Administration OrganizationExecutive Members in Promotion Eco-Tourism of Changwat Samut Prakarn. Thesis of Master of Art (Political Science), Kasetsart University.

Cronbach, L. J. (1951). Coefficient alpha and the internal structure of tests. Psychometrika, 16(3) : 297-334.

De Fleur, M.L. (1966). Theories of Mass Communication. New York : David Mckay.

Junton, B., Rangsiwong P. and Srisawat, P. (2004). Factors Influencing the Participation of Local Communities in Ecotourism Management along the Banks of the Mae Klong Rive, Ratchaburi Province. Research Report of Rajamangala University of Technology Krungthep. Middle Region Research Administration Network.

Kerstetter, D.L., Hou J.-S. and Lin C.-H. (2004). Profiling Taiwanese ecotourists using a behavioral approach. Tourism Management, 25(2004) : 491-498. 
Klabchum, N. (1991). Knowledge and Behavior of Teacher Student on Environmental Pollution in Bangkok. Thesis of Master of Education, Program of Environmental Education. Graduate Faculty, Mahidol University.

Kotler, P. (1994). Marketing Management : Analysis Planning Implementation and Control. $8^{\text {th }}$ ed. Englewood Cliffs : Prentrice Hall.

Nawajaroenkul, S. (1998). Ecotouristic behavior of the Thai tourists at Sai-Yoke national park, Karnchanaburi province. Thesis of Mater of Social Science, Program of Environment, Mahidol University.

Petcharoen, K. (2000). Guidelines on participation of people in Bangkok for green label products consumption. Thesis of Mater of Science. Program of Environmental Management Technology, Graduate Faculty, Mahidol University.

Prapannetivuth, A. and Arttacharija, P. (2008). Ecotourism: A Study on Responsible Environmental Behavior of Visitors to Selected Thai National Parks. AU Journal of Management. 6(1) : 12-23.

Suwattikul, A. (2005). Ecotourism Behaviors of Visitors to Kaeng Krachan National Park, Phetchaburi Province Thesis of Mater of Science. Program of Forest Resource Management, Kasetsart University.

Songserm, B. (2001). Consumer Psychological Factors for Predicting Eco-tourism Behavior of Tourists in Chiang Mai Province. Thesis of Mater of Science. Program of Industrial and Organizational Psychology, Chiang Mai University.

Theepapal, D. (1999). Consumption Behavior. Bangkok: Rungrueng Sarn Publishing.

Thiengkamol, N. (2011i). Development of Model of Environmental Education and Inspiration of Public Consciousness Influencing to Global Warming Alleviation. European Journal of Social Sciences, 25(4) : 506-514.

Watthamanee, S. (1999). The Relationship between Media Receiving on Ecotourism and Knowledge Attitude and Behavior of Undergrad student in Bangkok Metropolis. Thesis of Master of Arts Program in Mass Communication, Thammasart University.

Weerachaya, C. (2003). Media Exposure, Knowledge, Attitude on Eco-friendly Products Consumption: A Case Study of Fourth Year Student of Kasetsart University. Thesis Master of Science, Program Industrial Psychology. Kasetsart University.

Yamane, T. (1973). Statistic: An Introductory Analysis. 3 rd ed. New York: Harper and Row. 
